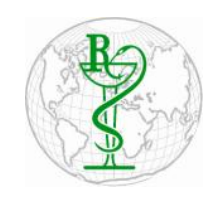

INDO GLOBAL JOURNAL OF

PHARMACEUTICAL SCIENCES

ISSN 2249- 1023

\title{
Enhancement of Dissolution Rate of Aceclofenac by Formation of Aceclofenac-Nicotinic Acid Cocrystal using Water Soluble Polymers like PVPK-30, HPMCE5, SSG and Na-CMC
}

\author{
Mohd Sohrab $^{1 *}$, S. P. Mahapatra ${ }^{2}$, Shashank Tiwari ${ }^{3}$ \\ ${ }^{1}$ Department of Pharmacy, Monad University, India \\ ${ }^{2}$ Department of Pharmacology, S.S. Medical College, India \\ ${ }^{3}$ Department of Pharmacy, IBRI, Lucknow, India
}

\begin{abstract}
Address for Correspondance Mohd Sohrab, shashank6889@g $\underline{\text { mail.com }}$
\end{abstract}

Keywords

Cocrystal;

Pharmaceutical

Cocrystal;

Cocrystal

Former; Water

Soluble Polymer,

Solvent

Evaporation;

Neat Grinding;

Solubility.
ABSTRACT: The objective of the present research was to formulate and characterize aceclofenac-nicotinic acid cocrystal and enhancement of dissolution rate of aceclofenac by using water soluble polymers like polyvinylpyrrolidone (PVPK-30), hydroxypropylmethyl cellulose (HPMCE5), sodium starch glycolate (SSG) and carboxymethylcellulose sodium (Na-CMC). Aceclofenac cocrystals were prepared by using drug aceclofenac (ACF) and cocrystal former nicotinic acid (NI) in (1:1 molar ratio), solvent dimethyl sulfoxide (DMSO) and 3\% water soluble polymers like PVPK-30, HPMCE5, SSG and Na-CMC by both solvent evaporation \& neat grinding method. Tablet for pure drug aceclofenac and various aceclofenac cocrystal formulations were prepared by wet granulation method using Cadmach single station tablet punching machine. The prepared tablet was subjected to in vitro dissolution study using eight station USP type-I (basket) dissolution apparatus in phosphate buffer, PH 7.5. Pure drug aceclofenac (ACF) showed $31.34 \%$ drug release. Aceclofenac cocrystal formulation without 3\% water soluble polymer like MUSE and MUNG showed drug release $78.98 \%$ and $78.51 \%$ respectively. Aceclofenac cocrystal formulation MUNG01 (containing 3\% PVPK30), MUNG02 (containing 3\% HPMCE5), MUSE03 (containing 3\% SSG) and MUSE04 (containing 3\% NaCMC) showed maximum drug release $99.1 \%, 97.51 \%, 99 \%$, and $98.25 \%$ respectively. The best formulations are MUSE, MUSE03, MUSE04, MUNG, MUNG01 and MUNG02. The best formulations were further evaluated by Fourier transform infrared (FTIR), Differential scanning calorimetry (DSC), Powder X-ray diffraction (PXRD) and Scanning electron microscopy (SEM).The result of analysis of FTIR, DSC, PXRD and SEM confirms the formation of a new solid phase i.e aceclofenac cocrystal.@ 2015 iGlobal Research and Publishing Foundation. All rights reserved.

\section{INTRODUCTION}

Pharmaceutical cocrystallisation is emerging as an attractive alternative to polymorphs, salts and solvates in the modification of an active pharmaceutical ingredient (API) during dosage form design. An alternative approach available for the enhancement of drug solubility, dissolution and bioavailability is through the application of crystal engineering of cocrystals, historically referred to as molecular complexes [1]. Apart from the improvements in solubility, dissolution rate, bioavailability and physical stability, pharmaceutical cocrystals can also enhance other essential properties of the APIs such as flowability, chemical stability, compressibility and hygroscopicity [2].

"A cocrystal is a multiple component crystal in which all components are solid under ambient conditions when in their pure form. These components co-exists as a stoichiometric ratio of a target molecule or ion and a 


\section{Indo Global Journal of Pharmaceutical Sciences, 2015; 5(3): 154-170}

neutral molecular cocrystal former(s)" [3].

Pharmaceutical cocrystals can be defined as "cocrystal forms composed of a stoichiometric ration of an API and a pharmaceutically acceptable cocrystal former." [4]

While the role of the API in the cocrystal is the origin of pharmacological activity, the purpose of the cocrystal former is to modify or generate a particular physicochemical property of the API solid form. Consequently, cocrystallisation can be referred to as noncovalent derivatisation [5]. Biopharmaceutical classification system (BCS) divides all active pharmaceutical ingredients (API) into four classes based on drug dissolution rate and gastrointestinal permeability. BCS class II is defined by drugs of high permeability and low solubility. High permeability is a positive trait of these drugs but low solubility poses a big challenge to formulation scientists [6]. In the pharmaceutical industry, it is the poor biopharmaceutical properties rather than toxicity or lack of efficacy that are the main reasons why less than $1 \%$ of active pharmaceutical compounds eventually appear into the marketplace Among these biopharmaceutical properties, solubility remains a key issue with drugs often discarded during commercial production due to their low solubility. Improving the solubility of drugs is currently one of the main challenges for the pharmaceutical industry. Many approaches have been adopted for improving the aqueous solubility of drugs including micronisation, salt formation, emulsification, solubilisations using co-solvents, and the use of polymer drug vehicles for delivery of poorly soluble drugs. Although these techniques have been shown to be effective at enhancing oral bioavailability, success of these approaches is dependent on the specific physicochemical nature of the molecules being studied. Over the last decade, there has been growing interests in the design of pharmaceutical cocrystals, which emerges as a potential method for enhancing the bioavailability of drugs with low aqueous solubility [7]. In order to achieve better therapeutic effect the drug should be absorbed from gastro-intestinal tract (GIT) in systemic circulation. The absorption of drug depends upon solubility and dissolution of drug. Mainly BCS class II drugs have disadvantage of variable solubility because they are characterized by low solubility and high permeability. These drugs show erratic absorption from GIT as solubility and dissolution is less. Thus bioavailability as well as therapeutic response will depend upon solubility and dissolution [8]. Aceclofenac is belongs to biopharmaceutics classification system (BCS) class II (low solubility, high permeability) [9]. Aceclofenac is a white or almost white, crystalline powder that is practically insoluble in water, freely soluble in acetone and soluble in alcohol. The solution in methanol shows an absorption maximum at $275 \mathrm{~nm}$. The solubility of aceclofenac, a weakly acidic drug ( $\mathrm{pKa} 4-5$ ), depends on $\mathrm{pH}$. Aceclofenac is highly soluble in basic conditions but relatively soluble in water and acidic $\mathrm{pH}$ conditions. Aceclofenac is practically insoluble in water so the improvement of aceclofenac dissolution is an important issue for enhancing its bioavailability and therapeutic efficacy [10].

Aceclofenac drug is selected for proposed work for the following reason:

1. Aceclofenac proved as effective as other Non-Steroidal Anti-Inflammatory Drug (NSAID) with lower indications of gastro-intestinal adverse effects and thus, resulted in a greater compliance with treatment.

2. Aceclofenac is well absorbed after oral administration with hepatic first pass metabolism.

3. It exhibits very slight solubility in water, poor flow and compression characteristics. Because of the poor aqueous solubility, aceclofenac poses a dissolution- related absorption problem [11].

4. The improvement of aceclofenac dissolution is an important issue for enhancing its bioavailability and therapeutic efficacy [12].

Chemical Structure of aceclofenac are shown (in figure 1). [13]

Nicotinic acid is a water-soluble vitamin of the B complex occurring in various animal and plant tissues. It is required by the body for the formation of coenzymes nicotinamide adenine dinucleotide (NAD) and nicotinamide adenine dinucleotide phosphate (NADP). It has Pellagra-curative, vasodilating, and antilipemic properties. Soluble in alcohol, insoluble in most lipid solvents. In water, $18,000 \mathrm{mg} / \mathrm{L}$ at $20{ }^{\circ} \mathrm{C}$. [14] Nicotinic Acid is pyridine-3-carboxylic acid. It is a white or creamy-white, crystalline powder [15]. Chemical Structure of nicotinic acid are shown (in figure 2) [16]. 


\section{Indo Global Journal of Pharmaceutical Sciences, 2015; 5(3): 154-170}

Dimethyl sulfoxide (DMSO) is an organosulfur compound with the formula (CH3)2SO. This colorless liquid is an important polar aprotic solvent that dissolves both polar and nonpolar compounds and is miscible in a wide range of organic solvents as well as water [17]. In 1989, Desiraju defined crystal engineering as "the understanding of intermolecular interactions in the context of crystal packing and in the utilization of such understanding in the design of new solids with desired physical and chemical properties."[18] Cocrystals are constructed from intermolecular interactions such as van der Waals contact forces, $\pi-\pi$ stacking, interactions, and hydrogen bonding. Crystal engineering involves modification of the crystal packing of a solid material by changing the intermolecular interactions that regulate the breaking and formation of non-covalent bonds, such as hydrogen bonding, van der Waals force, $\pi-\pi$ stacking, electrostatic interactions, and halogen bonding.[7]

The term 'supramolecular synthon' was introduced by Desiraju in 1995, and defined as 'structural units within supermolecules which can be formed and/or assembled by known or conceivable synthetic operations involving intermolecular interaction'[19]. Supramolecular synthons are spatial arrangements of intermolecular interactions; the overall goal of crystal engineering is therefore to recognise and design synthons that are robust enough to be interchanged between network structures. This ensures generality ultimately leading to the predictability of one-, two- and three-dimensional patterns formed by intermolecular interactions. [1] supramolecular synthon are further categorized into:

\section{Supramolecular homosynthon}

Composed of identical self-complementary functionalities.

\section{Supramolecular heterosynthons}

Composed of different but self-complementary functionalities [20].

The most common supramolecular synthons utilised in pharmaceutical cocrystals are shown in Figure.3. Existing widely in drugs, carboxylic acid functional group has been extensively studied in the pharmaceutical cocrystal research area. With self-complementary hydrogen bond donor and acceptor, the formation of carboxylic acid homosynthon in Fig. 3 (1) through $\mathrm{C} \mathrm{O} \cdot \cdots \cdot \mathrm{H}-\mathrm{O}$ hydrogen bond is very common. Another widely studied homosynthon is amide homodimer in Fig. 3 (3), forming a cocrystal through $\mathrm{C} \mathrm{O} \cdot \cdots \cdot \mathrm{H}-\mathrm{N}$ hydrogen bond. Apart from homosynthons, some favourable heterosynthons are also shown in Fig. 3, such as carboxylic acid-pyridine in Fig. 3 (2), carboxylic-amide in Fig. 3 (4), and alcoholether in Fig. 3 (5). Generally, heterosynthons are more robust than homosynthons, e.g., the acid-amide heterosynthons favoured over both carboxylic acid and amide homodimer. Among all the heterosynthons, one of the most widely used synthons has contained an $\mathrm{O}-\mathrm{H} \cdot$ • - $\mathrm{N}$ hydrogen bond, formed by carboxylic acid and a suitable $\mathrm{N}$-containing heterocycle such as carboxylic acid-pyridine heterosynthon shown in Fig. 3 (2). The Cambridge structural database (CSD) study indicated carboxylic acid-pyridine heterosynthons more favoured over carboxylic acid homodimers [7].<smiles>O=C(O)COC(=O)Cc1ccccc1Nc1c(Cl)cccc1Cl</smiles>

Figure.1 Aceclofenac<smiles>O=C(O)c1cccnc1</smiles>

Figure.2 Nicotinic acid

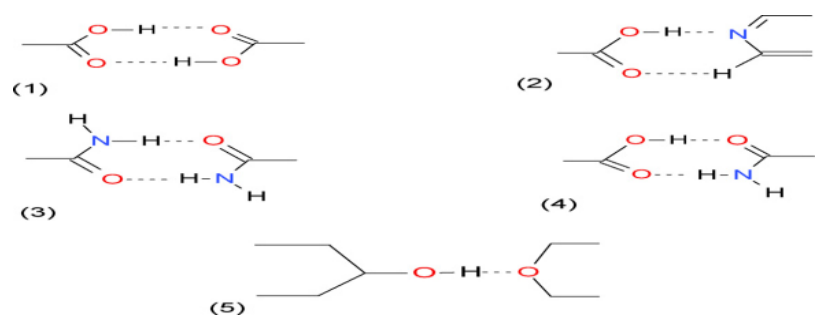

Figure.3. Typical hydrogen bonds utilised in crystal engineering.

The proposed research article utilized Carboxylic acid homosynthon and Carboxylic acid-pyridine heterosynthon. 
Indo Global Journal of Pharmaceutical Sciences, 2015; 5(3): 154-170

\section{MATERIALS \& METHODS}

\section{Materials}

Drug aceclofenac, hydroxypropylmethyl cellulose (HPMCE5), sodium starch glycolate (SSG) and carboxymethylcellulose sodium (Na-CMC) were purchased from Human Gold Kloo Pharmaceutical pvt. Ltd. China. Cocrystal former nicotinic acid and solvent dimethyl sulfoxide were purchased from S D Fine-Chem Limited. Mumbai, India. Polyvinylpyrrolidone (PVP K30) was purchased from Colourcon Asia Pvt. Ltd. Goa, India.

All chemical were purchased and provided by Hygia Institute of Pharmaceutical Education \& Research Lucknow, India. All chemical were of analytical grade and were used in the same form as received by Hygia laboratory.

\section{Methods}

Calibration curve of aceclofenac in phosphate buffer solution pH 7.5

The data for calibration curve of aceclofenac in phosphate buffer solution $\mathrm{pH} 7.5$ are shown in table.1. Calibration curve of aceclofenac in phosphate buffer solution $\mathrm{pH} 7.5$ are shown in figure.4. A stock solution containing 1 $\mathrm{mg} / \mathrm{mL}$ of pure drug was prepared by dissolving $50 \mathrm{mg}$ of aceclofenac in sufficient phosphate buffer solution (PBS), to produce $50 \mathrm{~mL}$ solution in a volumetric flask. $10 \mathrm{~mL}$ of the stock solution was further diluted to $100 \mathrm{~mL}$ with PBS to obtain a working standard solution containing $100 \mathrm{mcg} / \mathrm{mL}$. The aliquots working standard solution was diluted serially with sufficient PBS to obtain the concentration range of $10-100 \mathrm{mcg} / \mathrm{mL}$. A calibration curve for aceclofenac was obtained by measuring the absorbance at the $\lambda \max$ of $273 \mathrm{~nm}[\mathbf{2 1}]$.

\section{Method for aceclofenac cocrystal formation}

\section{Solvent evaporation method}

Accurately weighed quantity of drug aceclofenac (ACF) and cocrystal former nicotinic acid (NI) in (1:1 molar ratio) and 3\% water soluble polymers like polyvinylpyrrolidone (PVPK-30), hydroxypropylmethyl cellulose (HPMCE5), Sodium starch glycolate (SSG) and Carboxymethylcellulose sodium (Na-CMC) were dissolved in $1 \mathrm{ml}$ dimethyl sulfoxide (DMSO) and left for slow evaporation. After 7 days fine crystal obtained which were collected in a tight container and stored in desiccators. The composition of aceclofenac cocrystal prepared by solvent evaporation method are shown in Table. 2.

\section{$\underline{\text { Neat grinding method }}$}

Accurately weighed quantity of drug aceclofenac (ACF) and cocrystal former nicotinic acid (NI) in (1:1 molar ratio) and $3 \%$ water soluble polymers like polyvinylpyrrolidone (PVPK -30), hydroxypropylmethyl cellulose (HPMCE5), Sodium starch glycolate (SSG) and Carboxymethylcellulose sodium (Na-CMC) were ground in a mortar pestle for $1 \mathrm{hr}$, the powder were obtain collected in a tight container and stored in desiccators. Composition of aceclofenac cocrystal prepared by neat grinding method are shown in Table.3.

\section{Fourier transform infrared (FTIR)}

Pure drug aceclofenac (ACF) and cocrystal former nicotinic acid (NI) and aceclofenac cocrystal formulations like MUSE, MUSE03, MUSE04, MUNG, MUNG01 and MUNG02 were subjected for Fourier transform infrared (FTIR) Studies. Potassium bromide pellet method was employed for FTIR analysis. FTIR spectrophotometer (Perkin Elmer Spectrum Version 10.03.06) was employed and all the samples were scanned over a range of 4000 to $400 \mathrm{~cm}-1$.

Table.1. The data for calibration curve of aceclofenac in phosphate buffer solution $\mathbf{p H} 7.5$

\begin{tabular}{|c|c|}
\hline Concentration & Absorbance \\
\hline 0 & 0 \\
\hline 10 & 0.19 \\
\hline 20 & 0.36 \\
\hline 30 & 0.53 \\
\hline 40 & 0.7 \\
\hline 50 & 0.87 \\
\hline 60 & 1.04 \\
\hline 70 & 1.21 \\
\hline 80 & 1.38 \\
\hline 90 & 1.55 \\
\hline 100 & 1.72 \\
\hline
\end{tabular}




\section{Indo Global Journal of Pharmaceutical Sciences, 2015; 5(3): 154-170}

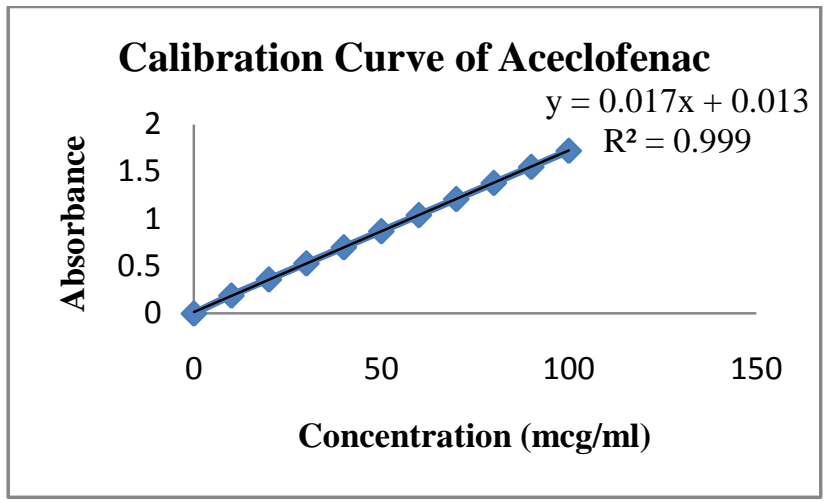

Figure.4. Calibration curve of aceclofenac in phosphate buffer solution pH 7.5

\section{Differential scanning calorimetry (DSC)}

Thermal analysis of pure drug aceclofenac (ACF) and cocrystal former nicotinic acid (NI) and aceclofenac cocrystal formulations like MUSE, MUSE03, MUSE04, MUNG, MUNG01 and MUNG02 were performed in a Mettler Toledo DSC 822e differential scanning calorimeter. DSC temperature and enthalpy scale was calibrated by using indium/zinc standards. The samples were sealed in aluminium pans and thermograms were obtained by heating at a constant rate $100 \mathrm{C} / \mathrm{min}$ over a temperature range of 30-3000C. Nitrogen gas was purged continuously at a flow rate of $50 \mathrm{ml} / \mathrm{min}$ for maintaining an inert atmosphere.

\section{Powder X-ray diffraction (PXRD)}

The PXRD pattern of pure drug aceclofenac (ACF) and cocrystal former nicotinic acid (NI) and aceclofenac cocrystal formulations like MUSE, MUSE03, MUSE04, MUNG, MUNG01 and MUNG02 were collected on a Bruker AXS D8 Advance powder diffractometer with $\mathrm{Cu}$ $\mathrm{K} \alpha$ radiation $\left(1.5406 \mathrm{~A}^{\circ}\right)$. The sample is smeared over low back ground sample holder (amorphous silica holder) and fixed on the sample stage in goniometer. The instrument is set with B-B geometry. Sample was scanned between $3^{\circ}$ and $80^{\circ}(2 \theta)$ with a step size of $0.020^{\circ}$ and $29.1 \mathrm{~s}$ at each step. The current and voltage is set to 40 $\mathrm{mV}$ and $35 \mathrm{~mA}$ and data has been collected.

\section{Scanning electron microscopy (SEM)}

The shape and surface characteristic of pure drug aceclofenac (ACF), cocrystal former nicotinic acid (NI) and aceclofenac cocrystal formulations like MUSE, MUSE03, MUSE04, MUNG, MUNG01 and MUNG02 were studied by scanning electron microscopy analysis. The sample is smeared on a small piece of adhesive carbon tape which is fixed on a brass stub. The sample, then subjected to gold coating using sputtering unit (model: JFC1600) for $10 \mathrm{sec}$ at $10 \mathrm{~mA}$ of current. The gold coated sample placed in chamber of SEM (Jeol, JSM 6390LA) and secondary electron/Back Scattered electron images are recorded.

Preparation of tablet containing pure drug aceclofenac $A C F)$ and various aceclofenac cocrystal formulations

Aceclofenac cocrystal formulations equivalent to $100 \mathrm{mg}$ of drug aceclofenac was used in the formation of tablet. Tablet containing pure drug aceclofenac and various aceclofenac cocrystal formulations were prepared by using excipient like diluents lactose, binder PVPK-30 (2\%), disintegrant microcrystalline cellulose $(5 \%)$, lubricants magnesium stearate (2\%) and solvent ethanol. The granules were prepared by wet granulation method and compressed into tablets by Cadmach single station tablet punching machine (M/s Cadmach Engineering Co. Pvt. Ltd., Mumbai) using $12 \mathrm{~mm}$ punches. The prepared tablet containing pure drug aceclofenac and aceclofenac cocrystal formulations were subjected to in vitro dissolution study. Formula for tablet containing pure drug aceclofenac (ACF) and various aceclofenac cocrystal formulations were given in Table 4 .

\section{In vitro dissolution studies}

The prepared tablet containing pure drug aceclofenac and aceclofenac cocrystal formulations were subjected to in vitro dissolution studies using eight station USP type-I (basket) dissolution apparatus (Electro Lab, TDT-08L, Mumbai, India). In vitro dissolution studies were carried out in $900 \mathrm{ml}$ phosphate buffer, $\mathrm{PH} 7.5$ at $37 \pm 0.5 \mathrm{oC}$. The basket speed was set at $50 \mathrm{rpm}$. $10 \mathrm{ml}$ sample was withdrawn from dissolution medium at time interval 15 , 30, 45 and 60 minute and immediately add $10 \mathrm{ml}$ fresh medium into the dissolution medium to keep the total volume constant. The withdrawn samples were analyzed spectrophotometrically at $273 \mathrm{~nm}$ using blank. 
Indo Global Journal of Pharmaceutical Sciences, 2015; 5(3): 154-170

Table 2. Composition of aceclofenac cocrystal prepared by solvent evaporation method

\begin{tabular}{llllll}
\hline Ingredients & MUSE & MUSE01 & MUSE02 & MUSE03 & MUSE04 \\
\hline Aceclofenac (ACF) (mg) & 354.2 & 354.2 & 354.2 & 354.2 & 354.2 \\
Nicotinic acid (NI) (mg) & 123.1 & 123.1 & 123.1 & 123.1 & 123.1 \\
Dimethyl sulfoxide (ml) & 1 & 1 & 1 & 1 & 1 \\
3\% PVPK-30 (mg) & - & 14.3 & - & - & - \\
3\% HPMCE5 (mg) & - & - & 14.3 & - & - \\
3\% Sodium starch glycolate (mg) & - & - & - & 14.3 & - \\
3\% Carboxymethylcellulose Sodium (mg) & - & - & - & - & 14.3 \\
\hline
\end{tabular}

Table 3. Composition of aceclofenac cocrystal prepared by neat grinding method

\begin{tabular}{llllll}
\hline Ingredients & MUNG & MUNG01 & MUNG02 & MUNG03 & MUNG04 \\
\hline Aceclofenac (ACF) (mg) & 354.2 & 354.2 & 354.2 & 354.2 & 354.2 \\
Nicotinic acid (NI) (mg) & 123.1 & 123.1 & 123.1 & 123.1 & 123.1 \\
Dimethyl sulfoxide (ml) & - & - & - & - & - \\
3\% PVPK-30 (mg) & - & 14.3 & - & - & - \\
3\% HPMCE5 (mg) & - & - & 14.3 & - & - \\
3\% Sodium starch glycolate (mg) & - & - & - & 14.3 & - \\
3\% Carboxy methyl cellulose Sodium (mg) & - & - & - & - & 14.3 \\
\hline
\end{tabular}

\section{RESULTS \& DISCUSSION}

Calibration curve of aceclofenac in phosphate buffer solution pH 7.5

The straight line equation of calibration curve of aceclofenac was $\mathrm{Y}=0.017 \mathrm{X}+0.013$ (where $\mathrm{Y}$ is absorbance and $\mathrm{X}$ is concentration in $\mathrm{mcg} / \mathrm{ml}$. Compare this equation to $\mathrm{Y}=\mathrm{mX}+\mathrm{C}$ we find the value of Slope $=$ 0.017 and the value of intercept $=0.013$. The value of coefficient of correlation was found 0.999 .

\section{Fourier transform infrared (FTIR)}

Fourier transform infrared (FTIR) spectra of pure drug aceclofenac (ACF) and cocrystal former nicotinic acid (NI) and aceclofenac cocrystal formulations like MUSE, MUSE03, MUSE04, MUNG, MUNG01 and MUNG02 are shown in figure. 5 and their peaks are shown in table. 5 to 12. In the FTIR spectrum of pure drug aceclofenac (ACF) the peaks at $770.11 \mathrm{~cm}-1,1757.57 \mathrm{~cm}-1$ and $3387.37 \mathrm{~cm}-1$, corresponding to $\mathrm{C}-\mathrm{Cl}$ stretch, $\mathrm{C}=\mathrm{O}$ and $\mathrm{O}-$ $\mathrm{H}$ stretch of carboxylic acid respectively. In the FTIR spectrum of cocrystal former nicotinic acid (NI) the peaks at $3021.15 \mathrm{~cm}-1$ and $1649.2 \mathrm{~cm}-1$, corresponding to $\mathrm{C}-\mathrm{H}$ stretch of aromatic and $\mathrm{C}=\mathrm{N}$ stretch of imine functional group of pyridine respectively. The frequency of $\mathrm{C}-\mathrm{Cl}$ stretch, $\mathrm{C}=\mathrm{O}$ and $\mathrm{O}-\mathrm{H}$ stretch of carboxylic acid of aceclofenac were also observed in aceclofenac cocrystal formulation. Similarly the frequency of C-H stretch of aromatic and $\mathrm{C}=\mathrm{N}$ stretch of imine functional group of nicotinic acid was also observed in aceclofenac cocrystal formulation. This showed that both aceclofenac and nicotinic acid are present in the new phase i.e aceclofenac cocrystal. The frequency of $\mathrm{C}-\mathrm{Cl}$ stretch of aceclofenac decrease from $770.11 \mathrm{~cm}-1$ to $770.06 \mathrm{~cm}-1,769.97 \mathrm{~cm}-1$, $762.72 \mathrm{~cm}-1,758.26 \mathrm{~cm}-1,769.58 \mathrm{~cm}-1$, and $762.83 \mathrm{~cm}-$ 1 in aceclofenac cocrystal formulations like MUSE, MUSE03, MUSE04, MUNG, MUNG01 and MUNG02 respectively implies that the $\mathrm{C}-\mathrm{Cl}$ stretch of aceclofenac participate in strong hydrogen bond. The frequency of $\mathrm{C}=\mathrm{O}$ stretch of carboxylic acid of aceclofenac decrease from $1757.57 \mathrm{~cm}-1$ to $1719.25 \mathrm{~cm}-1,1716.1 \mathrm{~cm}-1$, $1717.04 \mathrm{~cm}-1$ and $1717.15 \mathrm{~cm}-1$ in aceclofenac cocrystal formulations like MUSE04, MUNG, MUNG01 and 


\section{Indo Global Journal of Pharmaceutical Sciences, 2015; 5(3): 154-170}

MUNG02 respectively implies that the $\mathrm{C}=\mathrm{O}$ functional group of carboxylic acid participate in strong hydrogen bond. The frequency of O-H stretch of carboxylic acid of aceclofenac decrease from $3387.37 \mathrm{~cm}-1$ to $3375.44 \mathrm{~cm}-$ 1, $3376.66 \mathrm{~cm}-1$ and $3315.8 \mathrm{~cm}-1$ in aceclofenac cocrystal formulations like MUSE04, MUNG01and MUNG02 respectively implies that the $\mathrm{O}-\mathrm{H}$ functional group of carboxylic acid participate in strong hydrogen bond. The frequency of $\mathrm{O}-\mathrm{H}$ stretch of carboxylic acid of aceclofenac increase from $3387.37 \mathrm{~cm}-1$ to $3390.09 \mathrm{~cm}-1$, $3399.31 \mathrm{~cm}-1$ and $3399.64 \mathrm{~cm}-1$ in aceclofenac cocrystal formulations like MUSE, MUSE03 and MUNG respectively implies that the $\mathrm{O}-\mathrm{H}$ functional group of carboxylic acid participate in weak hydrogen bond. The frequency of $\mathrm{C}=\mathrm{N}$ stretch of imine functional group of nicotinic acid decrease from $1649.2 \mathrm{~cm}-1$ to $1645.1 \mathrm{~cm}-$ $1,1645.48 \mathrm{~cm}-11647.1 \mathrm{~cm}-1,1645.86 \mathrm{~cm}-1$ and 1639.73 cm-1 in aceclofenac cocrystal formulations like MUSE, MUSE03, MUSE04, MUNG and MUNG01 respectively implies that the $\mathrm{C}=\mathrm{N}$ imine functional group participate in strong hydrogen bond. The frequency of $\mathrm{C}-\mathrm{H}$ stretch of aromatic of nicotinic acid decrease from $3021.15 \mathrm{~cm}-1$ to $3019.28 \mathrm{~cm}-1,3019.6 \mathrm{~cm}-1,3019.59 \mathrm{~cm}-1$ and 3019.44 cm-1 in aceclofenac cocrystal formulations like MUSE, MUSE03, MUNG and MUNG01 respectively implies that the $\mathrm{C}-\mathrm{H}$ aromatic of nicotinic acid participate in strong hydrogen bond. MUSE04 and MUNG02 has C-H stretch aromatic frequency $3021.17 \mathrm{~cm}-1$ and $3021.34 \mathrm{~cm}-1$ equal to $\mathrm{C}-\mathrm{H}$ stretch of aromatic of nicotinic acid (3021.15 cm-1) also implies that the $\mathrm{C}-\mathrm{H}$ aromatic of nicotinic acid participate in hydrogen bond. The frequency of $\mathrm{C}=\mathrm{O}$ stretch of carboxylic acid of aceclofenac was not observed in formulations MUSE and MUSE03. The formulations MUSE and MUSE03 formed aceclofenac cocrystal by $\mathrm{C}-\mathrm{Cl}$ stretch and $\mathrm{O}-\mathrm{H}$ stretch of aceclofenac participating in hydrogen bonding. Similarly The frequency of $\mathrm{C}=\mathrm{N}$ stretch of imine functional group of nicotinic acid was not observed in formulation MUNG02.The formulation MUNG02 formed aceclofenac cocrystal by $\mathrm{C}-\mathrm{H}$ stretch of aromatic of nicotinic acid participating in hydrogen bonding. Comparison of fourier transform infrared (FTIR) spectra of pure drug aceclofenac (ACF) and cocrystal former nicotinic acid (NI) and aceclofenac cocrystal formulations like MUSE, MUSE03, MUSE04, MUNG, MUNG01 and MUNG02 are shown in Table.13.

Aceclofenac cocrystal formed by hydrogen bonding of drug aceclofenac and cocrystal former nicotinic acid.
Aceclofenac cocrystal formed by utilizing carboxylic acid-carboxylic acid homosynthon and carboxylic acidpyridine heterosynthon. Aceclofenac has carboxylic acid functional group. Nicotinic acid has pyridine ring and carboxylic acid functional group. The carboxylic acidcarboxylic acid homosynthon was formed by carboxylic acid functional group of aceclofenac and carboxylic acid functional group of nicotinic acid by using $\mathrm{C} \mathrm{O} \cdot \cdots \cdot \mathrm{H}-\mathrm{O}$ hydrogen bond. Figure.3 (1). The carboxylic acidpyridine heterosynthon was formed by carboxylic acid functional group of aceclofenac and pyridine of nicotinic acid by using $\mathrm{O}-\mathrm{H} \bullet \cdot \mathrm{N}$ hydrogen bond. Figure. 3(2). Carboxylic acid functional group of aceclofenac participate in hydrogen bonding is confirmed by FTIR spectra of drug aceclofenac. Pyridine ring of nicotinic acid participate in hydrogen bonding is confirmed by FTIR spectra of nicotinic acid.

\section{Differential scanning calorimetry (DSC)}

The DSC thermograms of pure drug aceclofenac (ACF) and cocrystal former nicotinic acid (NI) and aceclofenac cocrystal formulations like MUSE, MUSE03, MUSE04, MUNG, MUNG01 and MUNG02 are shown in figure.6. The DSC thermograms of pure drug aceclofenac (ACF) showed a sharp endothermic peak at $152.66{ }^{\circ} \mathrm{C}$ corresponding to its melting point. Similarly the DSC thermograms of cocrystal former nicotinic acid (NI) showed a sharp endothermic peak at $235.61{ }^{\circ} \mathrm{C}$ corresponding to its melting point. The DSC thermograms of aceclofenac cocrystal formulations like MUSE, MUSE03, MUSE04, MUNG, MUNG01 and MUNG02 showed a sharp endothermic peak at $81.24{ }^{\circ} \mathrm{C}, 81.30{ }^{\circ} \mathrm{C}$, $81.12^{\circ} \mathrm{C}, \quad 138.12{ }^{\circ} \mathrm{C}, \quad 137.10{ }^{\circ} \mathrm{C}$ and $137.49{ }^{\circ} \mathrm{C}$ corresponding to its melting point respectively. Aceclofenac cocrystal formulations like MUSE, MUSE03, MUSE04, MUNG, MUNG01 and MUNG02 has lower melting point from those of aceclofenac and nicotinic acid. The melting point lowering of aceclofenac cocrystal formulation is due to increase in dissolution rate of drug aceclofenac in cocrystal formulation. The melting point of aceclofenac cocrystal formulations like MUSE, MUSE03, MUSE04, MUNG, MUNG01 and MUNG02 were different from those of aceclofenac and nicotinic acid which confirms the formation of a new solid phase i.e aceclofenac cocrystal. 


\section{Indo Global Journal of Pharmaceutical Sciences, 2015; 5(3): 154-170}

\section{Powder X-ray diffraction (PXRD)}

The PXRD patterns of pure drug aceclofenac (ACF) and cocrystal former nicotinic acid (NI) and aceclofenac cocrystal formulations like MUSE, MUSE03, MUSE04, MUNG, MUNG01 and MUNG02 are shown in figure.7. The PXRD patterns of pure drug aceclofenac (ACF) showed sharp peaks which confirm the crystalline nature of aceclofenac. Similarly the PXRD patterns of nicotinic acid (NI) showed sharp peaks which confirm the crystalline nature of nicotinic acid. The PXRD patterns of aceclofenac cocrystal formulations like MUSE, MUSE03, MUSE04, MUNG, MUNG01 and MUNG02 also showed sharp peaks which confirm the crystalline nature of these aceclofenac cocrystal formulations. The peaks intensity of various aceclofenac cocrystal formulations like MUSE, MUSE03, MUSE04, MUNG, MUNG01 and MUNG02 is lower from those of aceclofenac and nicotinic acid. The lowering in peaks intensity of these aceclofenac cocrystal formulations is due to increase in dissolution rate of drug aceclofenac in aceclofenac cocrystal formulations. The PXRD patterns of aceclofenac cocrystal formulations like MUSE, MUSE03, MUSE04, MUNG, MUNG01 and MUNG02 were different from drug aceclofenac (ACF) and nicotinic acid (NI) which confirms the formation of a new solid phase i.e aceclofenac cocrystal. The comparison of high intensity peaks of aceclofenac (ACF), nicotinic acid (NI) and various aceclofenac cocrystal formulations are shown in Table.14.

\section{Scanning Electron Microscopy (SEM)}

SEM images of pure drug aceclofenac (ACF) and cocrystal former nicotinic acid (NI) and aceclofenac cocrystal formulations like MUSE, MUSE03, MUSE04, MUNG, MUNG01 and MUNG02 are shown in figure.8. The size and shape of aceclofenac cocrystal formulations like MUSE, MUSE03, MUSE04, MUNG, MUNG01 and MUNG02 were different from pure drug aceclofenac and cocrystal former nicotinic acid which confirms the formation of a new solid phase i.e aceclofenac cocrystal. The particle size of MUNG, MUNG01 and MUNG02 were found smaller than MUSE, MUSE03, and MUSE04.

\section{In vitro dissolution studies}

In vitro dissolution profile of pure drug aceclofenac (ACF) and various aceclofenac cocrystal formulations formed by both solvent evaporation and neat grinding method are shown in figure.9. Pure drug aceclofenac (ACF) showed $31.34 \%$ drug release in $60 \mathrm{~min}$ Aceclofenac cocrystal formulation without $3 \%$ water soluble polymer like MUSE (containing ACF+NI) formed by solvent evaporation method showed $78.98 \%$ drug release in $60 \mathrm{~min}$. Similarly aceclofenac cocrystal formulations like MUSE01, MUSE02, MUSE03 and MUSE04 (containing 3\% water soluble polymer) formed by solvent evaporation method showed $85.87 \%, 80.78 \%$, $99 \%$ and $98.25 \%$ drug release in $60 \mathrm{~min}$. respectively. Aceclofenac cocrystal formulation without 3\% water soluble polymer like MUNG (containing $\mathrm{ACF}+\mathrm{NI}$ ) formed by neat grinding method showed $78.51 \%$ drug release in 60 min. Similarly aceclofenac cocrystal formulations like MUNG01, MUNG02, MUNG03 and MUNG04 (containing 3\% water soluble polymer) formed by neat grinding method showed $99.1 \%, 97.51 \%, 79.3 \%$ and $81.9 \%$ drug release in $60 \mathrm{~min}$. Pure drug aceclofenac (ACF) showed $31.34 \%$ drug release due to low solubility and dissolution rate of drug aceclofenac. The formation of aceclofenac-nicotinic acid cocrystal (formulations like MUSE and MUNG) increase the drug release of aceclofenac from $31.34 \%$ to $78.98 \%$ and $78.51 \%$ respectively.

This showed that the dissolution rate of aceclofenac enhanced by formation of aceclofenac-nicotinic acid cocrystal. The addition of $3 \%$ water soluble polymer in aceclofenac-nicotinic acid cocrystal (formulations like MUSE01, MUSE02, MUSE03, MUSE04, MUNG01, MUNG02, MUNG03 and MUNG04) increase the drug release of aceclofenac from $31.34 \%$ to $85.87 \%, 80.78 \%$, $99 \%, 98.25 \%, 99.1 \%, 97.51 \%, 79.3 \%$ and $81.9 \%$ respectively. This showed that the addition of $3 \%$ water soluble polymer like PVPK-30, HPMCE5, SSG and Na$\mathrm{CMC}$ in aceclofenac-nicotinic acid cocrystal further enhanced the dissolution rate of aceclofenac. Aceclofenac cocrystal formulation MUNG01 (containing 3\% PVPK30), MUNG02 (containing 3\% HPMCE5), MUSE03 (containing 3\% SSG) and MUSE04 (containing 3\% Na$\mathrm{CMC}$ ) showed maximum dissolution rate enhancement of drug aceclofenac because they showed maximum drug release $99.1 \%, 97.51 \%, 99 \%$, and $98.25 \%$ respectively. This showed that $3 \%$ water soluble polymers like PVPK30, HPMCE5, SSG and Na-CMC acts as dissolution improving ingredients in aceclofenac-nicotinic acid cocrystal. 
Indo Global Journal of Pharmaceutical Sciences, 2015; 5(3): 154-170

Table 4. Formula for Tablet containing pure drug aceclofenac (ACF) and various aceclofenac cocrystal formulations

\begin{tabular}{|c|c|c|c|c|c|c|c|c|c|c|c|}
\hline Ingredients & $\mathbf{A C F}$ & MUSE & MUSE01 & MUSE02 & MUSE03 & MUSE04 & MUNG & MUNG01 & MUNG02 & MUNG03 & MUNG04 \\
\hline Aceclofenac & 100 & - & - & - & - & - & - & - & - & - & - \\
\hline \multicolumn{12}{|l|}{ Amt. of cocrystal } \\
\hline Equivalent to & - & 135 & 139 & 139 & 139 & 139 & 135 & 139 & 139 & 139 & 139 \\
\hline \multicolumn{12}{|l|}{$100 \mathrm{mg}$ drug } \\
\hline Lactose & 173 & 138 & 134 & 134 & 134 & 134 & 138 & 134 & 134 & 134 & 134 \\
\hline PVPK-30 & 6 & 6 & 6 & 6 & 6 & 6 & 6 & 6 & 6 & 6 & 6 \\
\hline $\begin{array}{l}\text { Microcrystalline } \\
\text { cellulose }\end{array}$ & 15 & 15 & 15 & 15 & 15 & 15 & 15 & 15 & 15 & 15 & 15 \\
\hline $\begin{array}{l}\text { Magnesium } \\
\text { stearate }\end{array}$ & 6 & 6 & 6 & 6 & 6 & 6 & 6 & 6 & 6 & 6 & 5 \\
\hline Ethanol & q.s & q.s & q.s & q.s & q.s & q.s & q.s & q.s & q.s & q.s & q.s \\
\hline \multicolumn{12}{|l|}{ Total weight of } \\
\hline Tablet (in mg) & 300 & 300 & 300 & 300 & 300 & 300 & 300 & 300 & 300 & 300 & 300 \\
\hline
\end{tabular}


Indo Global Journal of Pharmaceutical Sciences, 2015; 5(3): 154-170

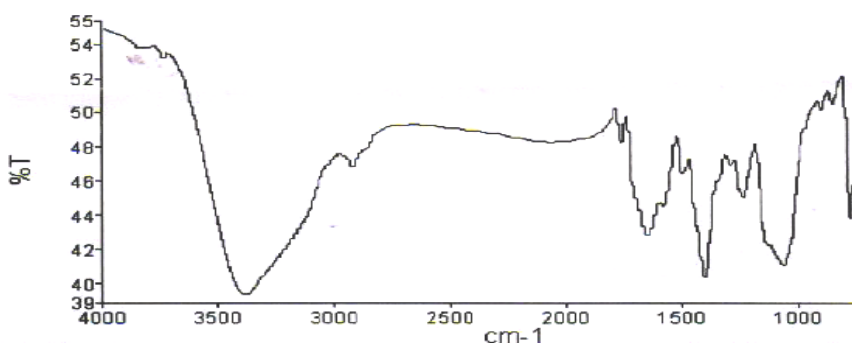

(a) Aceclofenac (ACF)

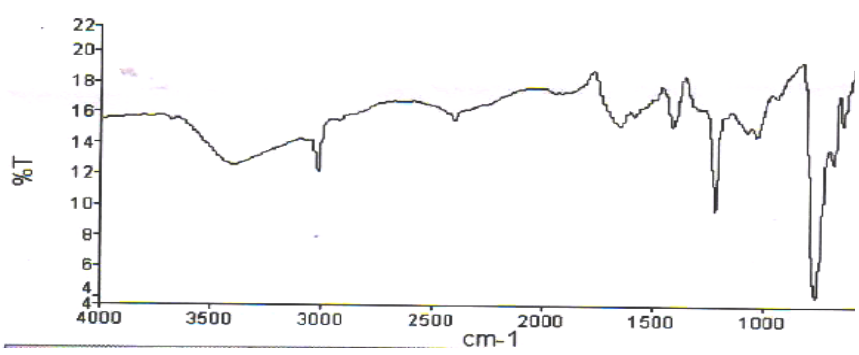

(b) Nicotinic acid (NI)

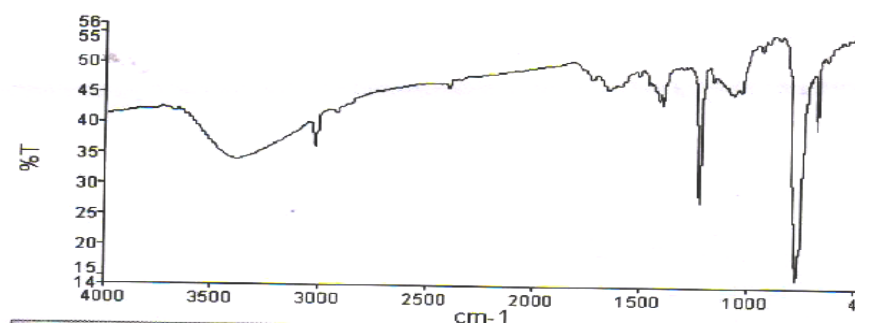

(c) MUSE

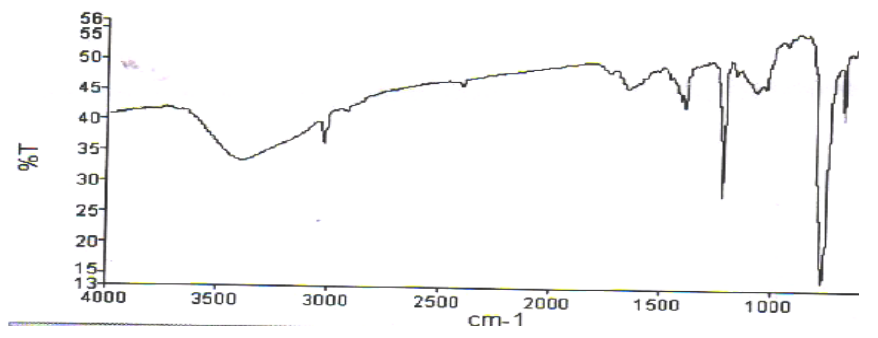

(d) MUSE03

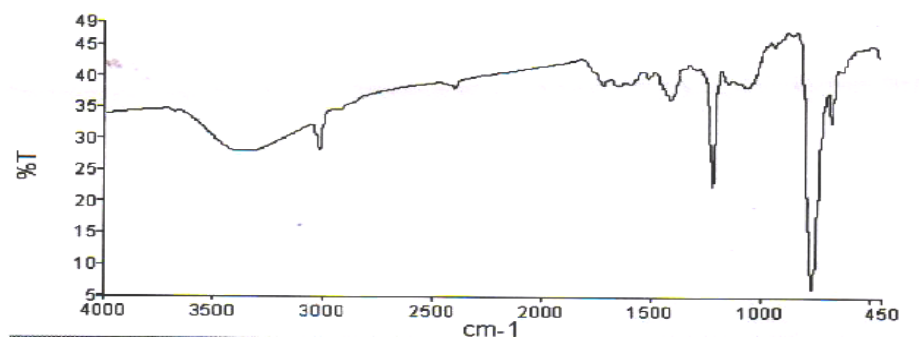

(e) MUSE04

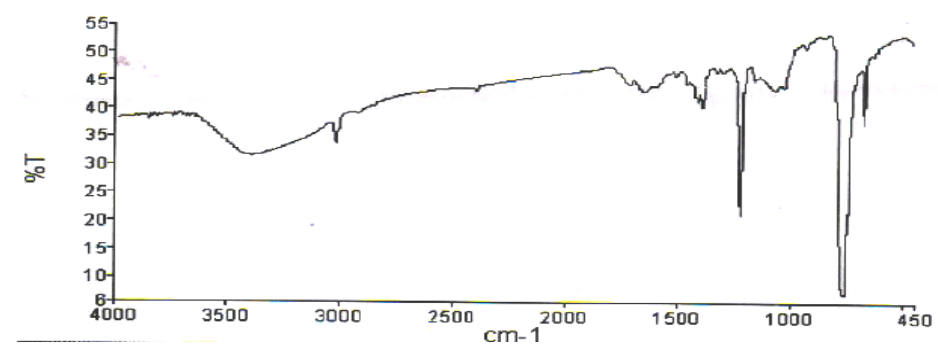

(f) MUNG

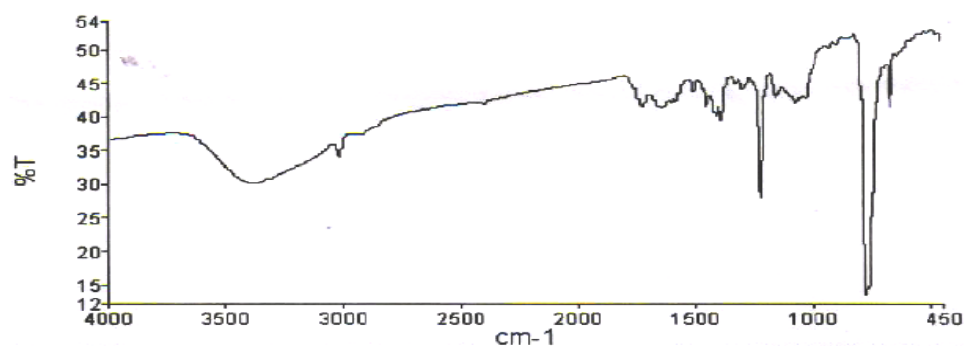

(g) MUNG01

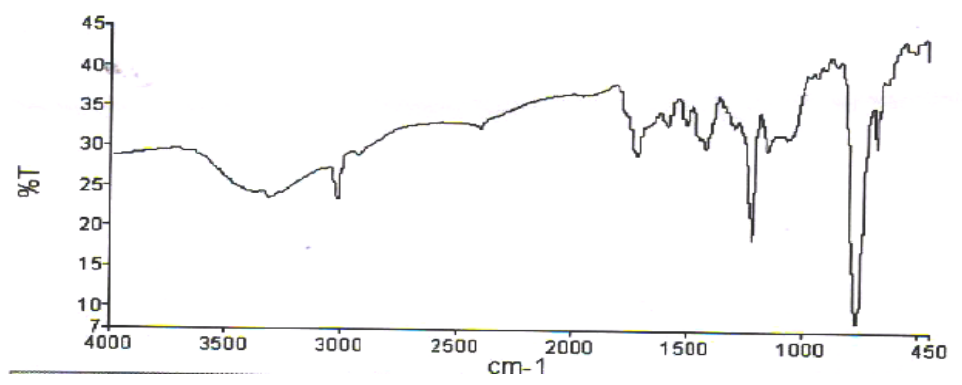

(h) MUNG02

Figure 5. FTIR spectra for (a) Aceclofenac (ACF) (b) Nicotinic acid (NI) (c) MUSE (d) MUSE03

(e) MUSE04 (f) MUNG (g) MUNG01 (h) MUNG02 
Indo Global Journal of Pharmaceutical Sciences, 2015; 5(3): 154-170

Table 5. Peak Table for ACF

\begin{tabular}{|l|l|l|}
\hline $\begin{array}{l}\text { Peak } \\
\text { Name }\end{array}$ & $\mathbf{X}$ & $\mathbf{Y}$ \\
\hline 10 & 608.41 & 50.54 \\
9 & 663.84 & 50.44 \\
8 & 770.11 & 43.85 \\
7 & 1056.27 & 41.09 \\
6 & 1228.89 & 45.11 \\
5 & 1397.68 & 40.39 \\
4 & 1644.99 & 42.82 \\
3 & 1757.57 & 48.32 \\
2 & 2061.74 & 48.32 \\
1 & 3387.37 & 39.32 \\
\hline
\end{tabular}

Table 7. Peak Table for MUSE

\begin{tabular}{|c|c|c|}
\hline $\begin{array}{c}\text { Peak } \\
\text { Name }\end{array}$ & $\mathbf{X}$ & $\mathbf{Y}$ \\
\hline 10 & 668.96 & 39.69 \\
9 & 770.06 & 14.64 \\
8 & 928.15 & 52.8 \\
7 & 1068.5 & 45.27 \\
6 & 1215.79 & 27.5 \\
5 & 1385.08 & 43.49 \\
4 & 1403.05 & 44.33 \\
3 & 1645.1 & 46.13 \\
2 & 3019.28 & 36.15 \\
1 & 3390.09 & 34.09 \\
& & \\
\hline
\end{tabular}

Table 9. Peak Table for MUSE04

\begin{tabular}{|c|c|c|}
\hline $\begin{array}{c}\text { Peak } \\
\text { Name }\end{array}$ & $\mathbf{X}$ & $\mathbf{Y}$ \\
\hline 11 & 669.38 & 32.84 \\
10 & 762.72 & 5.95 \\
9 & 1059.99 & 38.54 \\
8 & 1215.54 & 22.6 \\
7 & 1408.77 & 36.63 \\
6 & 1506.34 & 40.06 \\
5 & 1647.1 & 38.75 \\
4 & 1719.25 & 38.85 \\
3 & 2401.73 & 38.34 \\
2 & 3021.17 & 28.46 \\
1 & 3375.44 & 28.04 \\
& & \\
\hline
\end{tabular}

Table 6. Peak Table for NI

\begin{tabular}{|l|l|l|}
\hline $\begin{array}{l}\text { Peak } \\
\text { Name }\end{array}$ & $\mathbf{X}$ & $\mathbf{Y}$ \\
\hline 13 & 491.07 & 19.22 \\
12 & 633.04 & 15.26 \\
11 & 673.88 & 12.73 \\
10 & 762.1 & 3.94 \\
9 & 1026.42 & 14.6 \\
8 & 1068.8 & 14.89 \\
7 & 1214.72 & 9.74 \\
6 & 1408.71 & 15.15 \\
5 & 1582.11 & 15.84 \\
4 & 1649.2 & 15.27 \\
3 & 2400.96 & 15.6 \\
2 & 3021.15 & 12.14 \\
1 & 3398.78 & 12.59 \\
& & \\
\hline
\end{tabular}

Table 8. Peak Table for MUSE03

\begin{tabular}{|c|c|c|}
\hline $\begin{array}{c}\text { Peak } \\
\text { Name }\end{array}$ & X & Y \\
\hline 10 & 669.02 & 40.9 \\
9 & 769.97 & 14.16 \\
8 & 1067.96 & 45.5 \\
7 & 1154.57 & 48.23 \\
6 & 1215.86 & 28.28 \\
5 & 1385.04 & 42.94 \\
4 & 1402.46 & 44.12 \\
3 & 1645.48 & 45.94 \\
2 & 3019.6 & 36.21 \\
1 & 3399.31 & 33.52 \\
& & \\
\hline
\end{tabular}

Table 10. Peak Table for MUNG

\begin{tabular}{|c|c|c|}
\hline $\begin{array}{c}\text { Peak } \\
\text { Name }\end{array}$ & X & Y \\
\hline 10 & 668.98 & 37.5 \\
9 & 758.26 & 6.9 \\
8 & 1068.41 & 43.57 \\
7 & 1215.62 & 21.25 \\
6 & 1385.11 & 40.79 \\
5 & 1403.03 & 41.6 \\
4 & 1645.86 & 43.36 \\
3 & 1716.1 & 44.54 \\
2 & 3019.59 & 33.73 \\
1 & 3399.64 & 31.63 \\
& & \\
\hline
\end{tabular}


Indo Global Journal of Pharmaceutical Sciences, 2015; 5(3): 154-170

Table 11. Peak Table for MUNG01

\begin{tabular}{|c|c|c|}
\hline $\begin{array}{c}\text { Peak } \\
\text { Name }\end{array}$ & $\mathbf{X}$ & $\mathbf{Y}$ \\
\hline 14 & 668.77 & 41.8 \\
13 & 769.58 & 13.28 \\
12 & 1068.46 & 42.4 \\
11 & 1151.8 & 43.5 \\
10 & 1215.92 & 28.07 \\
9 & 1295.76 & 44.54 \\
8 & 1385.06 & 39.71 \\
7 & 1403.38 & 40.39 \\
6 & 1452.39 & 41.77 \\
5 & 1505.98 & 44.08 \\
4 & 1639.73 & 41.46 \\
3 & 1717.04 & 41.58 \\
2 & 3019.44 & 34.04 \\
1 & 3376.66 & 30.12 \\
& & \\
\hline
\end{tabular}

Table 12. Peak Table for MUNG02

\begin{tabular}{|c|c|c|}
\hline $\begin{array}{c}\text { Peak } \\
\text { Name }\end{array}$ & $\mathbf{X}$ & $\mathbf{Y}$ \\
\hline 13 & 512.19 & 42.48 \\
12 & 669.69 & 30.26 \\
11 & 762.83 & 8.2 \\
10 & 1146.67 & 29.94 \\
9 & 1216.2 & 18.63 \\
8 & 1290.76 & 32.81 \\
7 & 1414.41 & 30.2 \\
6 & 1504.59 & 32.98 \\
5 & 1585.35 & 32.92 \\
4 & 1717.15 & 29.01 \\
3 & 2402.29 & 32.4 \\
2 & 3021.34 & 23.44 \\
1 & 3315.8 & 23.35 \\
& & \\
\hline
\end{tabular}

Table.13. Comparison of Fourier Transform Infrared (FTIR) spectra of Pure drug aceclofenac (ACF) and cocrystal former nicotinic acid (NI) and aceclofenac cocrystal formulations like MUSE, MUSE03, MUSE04, MUNG, MUNG01 and MUNG02

\begin{tabular}{lllllllll}
\hline Functional group & ACF & NI & MUSE & MUSE03 & MUSE04 & MUNG & MUNG01 \\
\hline C-Cl stretch & 770.11 & - & 770.06 & 769.97 & 762.72 & 758.26 & 769.58 & 762.83 \\
C=O stretch of acid & 1757.57 & - & - & - & 1719.25 & 1716.1 & 1717.04 & 1717.15 \\
O-H stretch of acid & 3387.37 & - & 3390.09 & 3399.31 & 3375.44 & 3399.64 & 3376.66 & 3315.8 \\
C-H stretch of aromatic & - & 3021.15 & 3019.28 & 3019.6 & 3021.17 & 3019.59 & 3019.44 & 3021.34 \\
C=N stretch of imine & - & 1649.2 & 1645.1 & 1645.48 & 1647.1 & 1645.86 & 1639.73 & - \\
\hline
\end{tabular}

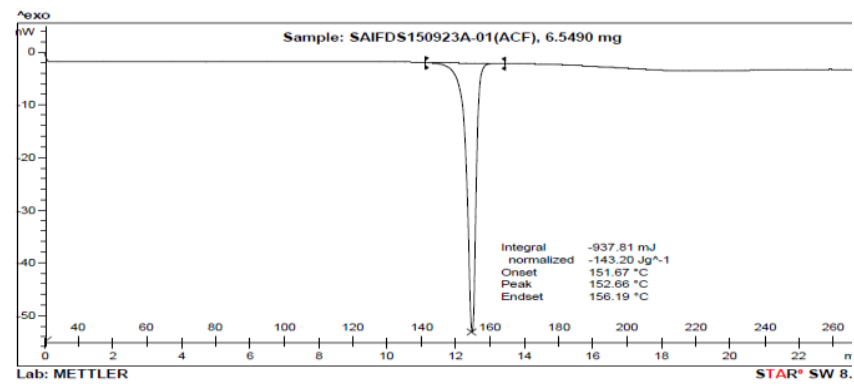

(a) Aceclofenac (ACF)

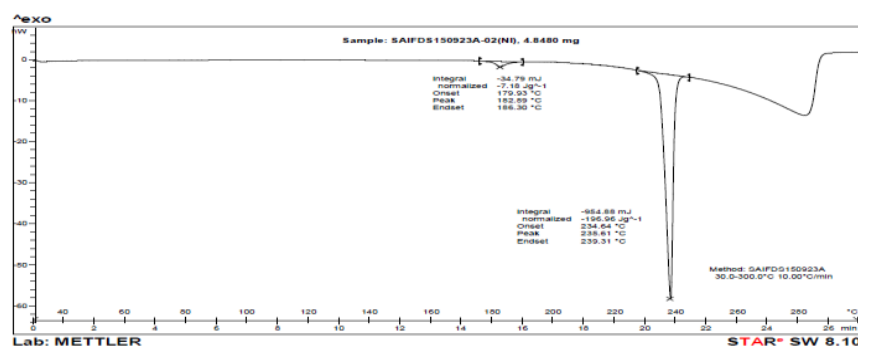

(b) Nicotinic acid (NI)

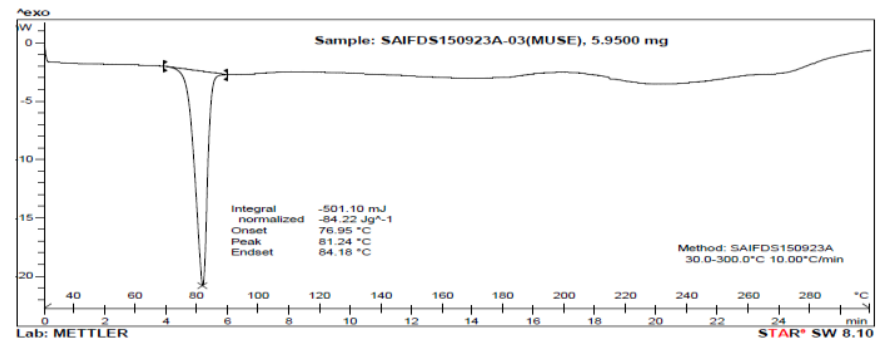

(c) MUSE

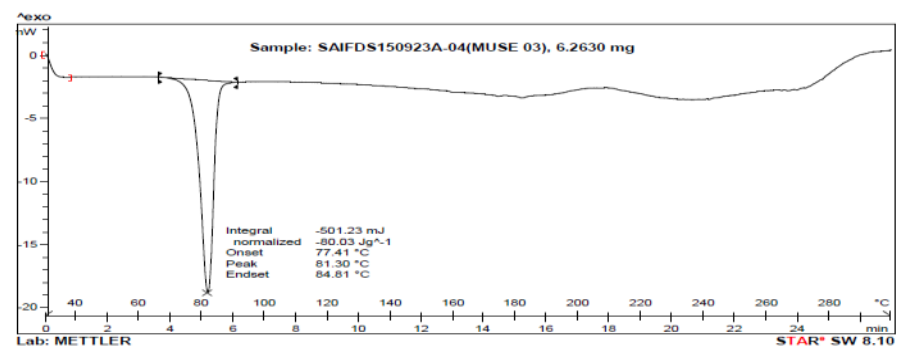

(d) MUSE03 
Indo Global Journal of Pharmaceutical Sciences, 2015; 5(3): 154-170

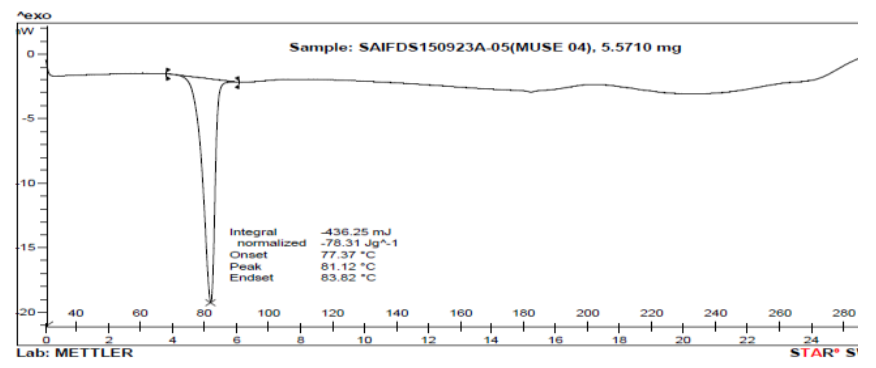

(e) MUSE04

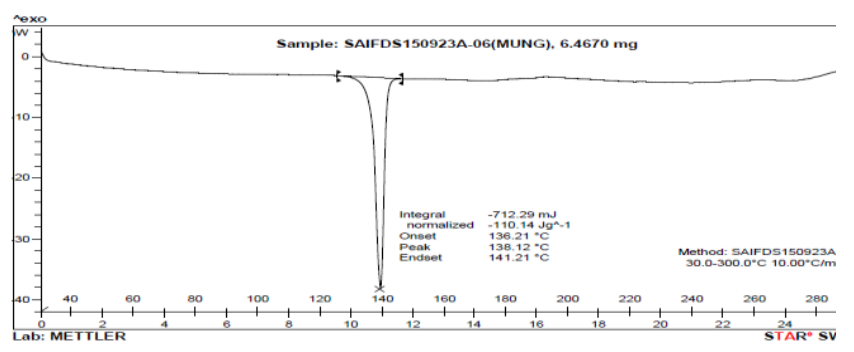

(f) MUNG

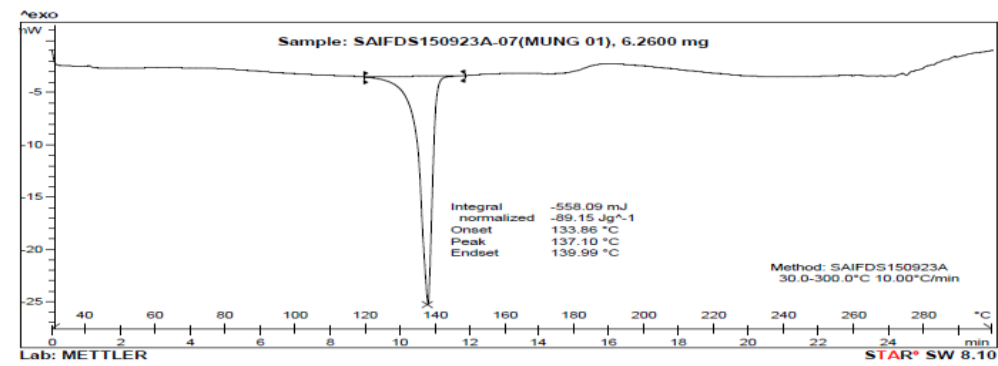

(g) MUNG01

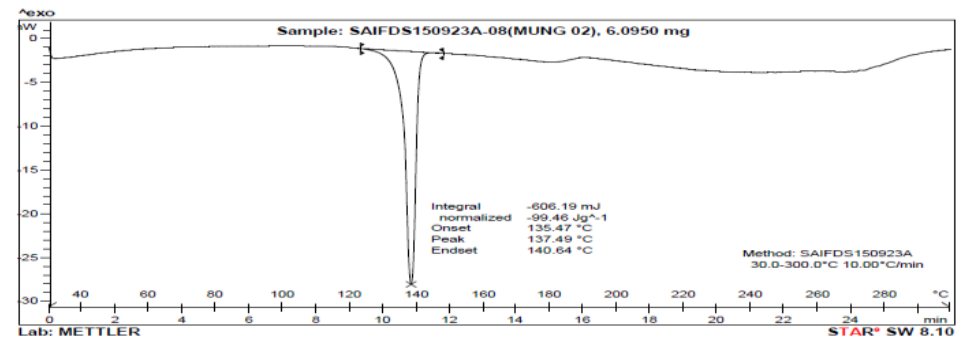

(h) MUNG02

Figure 6. The DSC thermograms of (a) Aceclofenac (ACF) (b) Nicotinic acid (NI) (c) MUSE (d)MUSE03 (e) MUSE04 (f) MUNG (g) MUNG01 (h) MUNG02

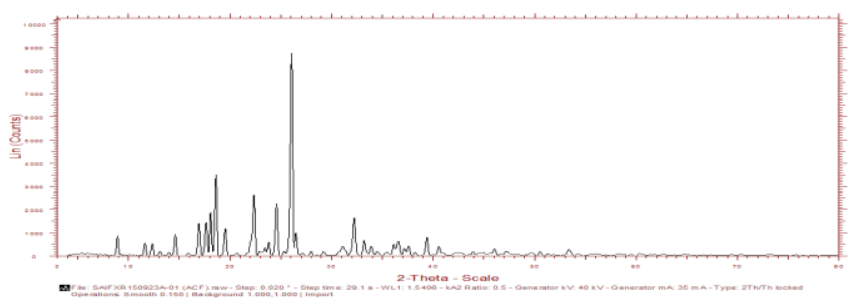

(a) Aceclofenac (ACF)

NI

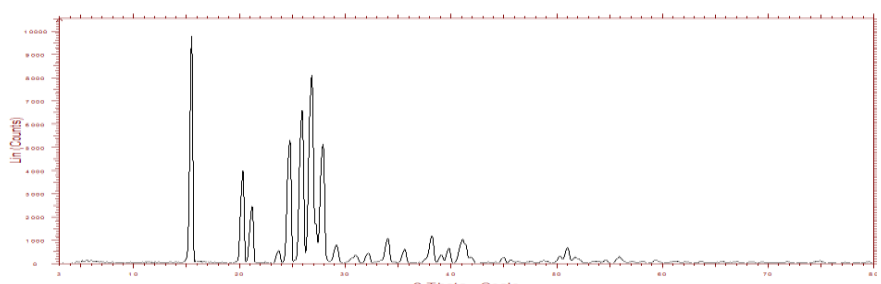

(b) Nicotinic acid (NI)

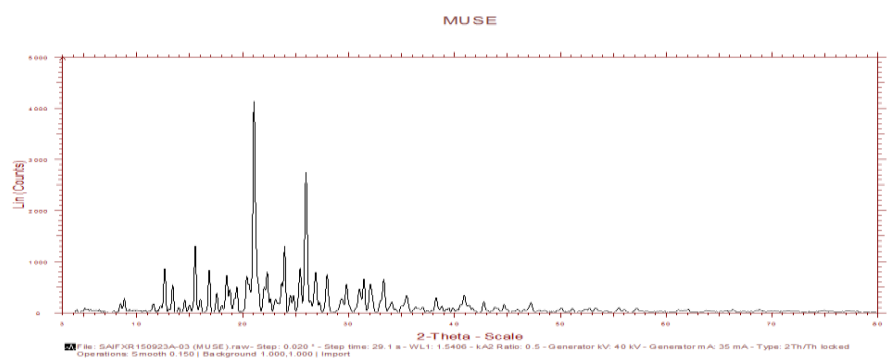

(c) MUSE

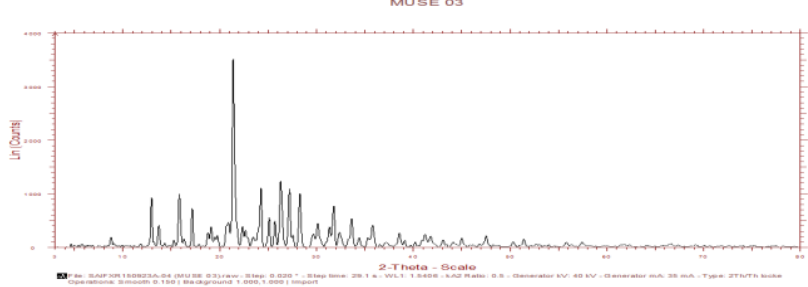

(d) MUSE03 
Indo Global Journal of Pharmaceutical Sciences, 2015; 5(3): 154-170

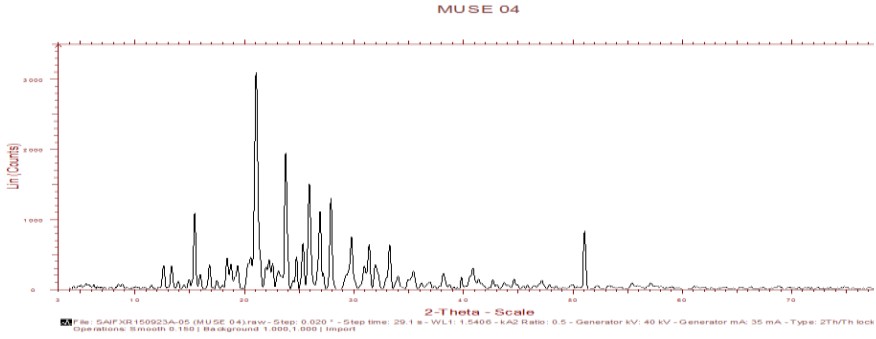

(e) MUSE04

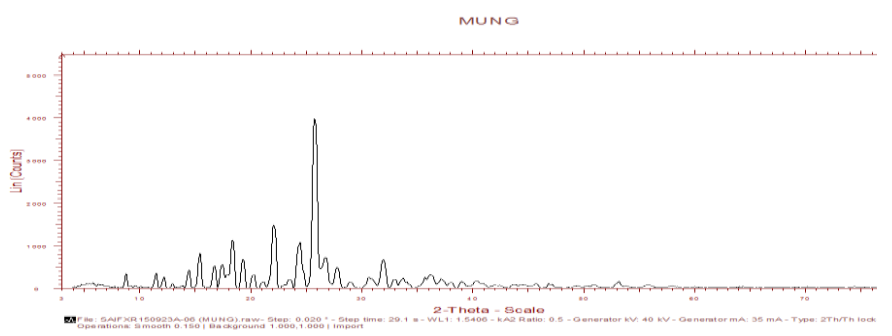

(f) MUNG

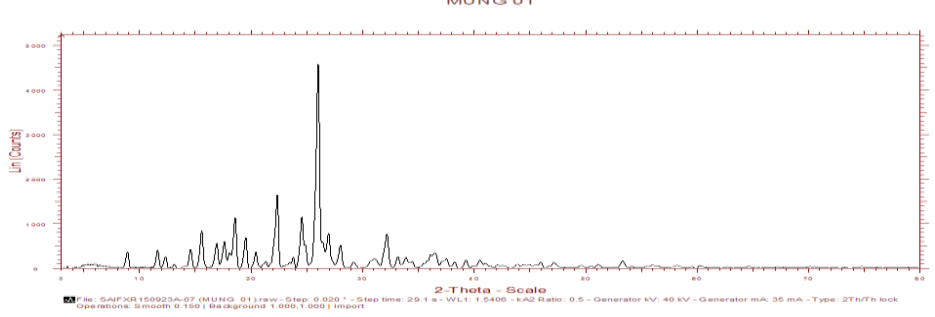

(g) MUNG01

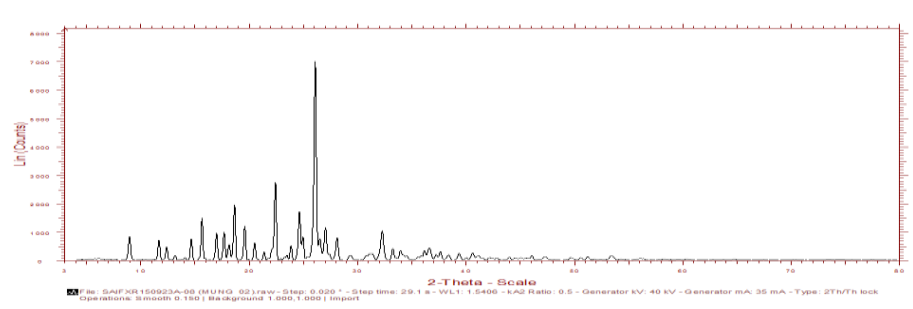

(h) MUNG02

Figure 7. The PXRD patterns of (a) Aceclofenac (ACF) (b) Nicotinic acid (NI) (c) MUSE (d) MUSE03 (e) MUSE04 (f) MUNG (g) MUNG01 (h) MUNG02

Table 14. The comparison of high intensity peaks of aceclofenac (ACF), nicotinic acid (NI) and various aceclofenac cocrystal formulations.

\begin{tabular}{lcccc}
\hline Formulations & 2-Theta (Degree) & d-value(Angstrom) & Intensity Count & \% Intensity \\
\hline ACF & 25.988 & 3.42580 & 8772 & 100 \\
NI & 15.373 & 5.75916 & 9797 & 100 \\
MUSE & 21.016 & 4.22372 & 4129 & 100 \\
MUSE03 & 21.331 & 4.16212 & 3516 & 100 \\
MUSE04 & 20.979 & 4.23113 & 3095 & 100 \\
MUNG & 25.691 & 3.46483 & 3986 & 100 \\
MUNG01 & 25.941 & 3.43201 & 4591 & 100 \\
MUNG02 & 26.015 & 3.42240 & 7030 & 100
\end{tabular}


Indo Global Journal of Pharmaceutical Sciences, 2015; 5(3): 154-170

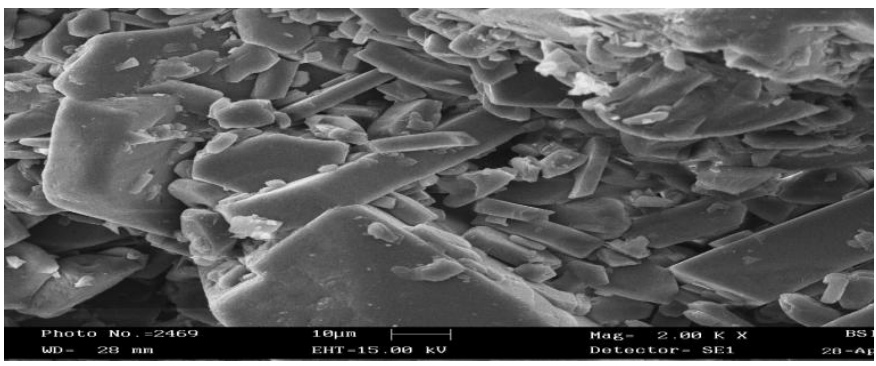

(a) Aceclofenac (ACF)

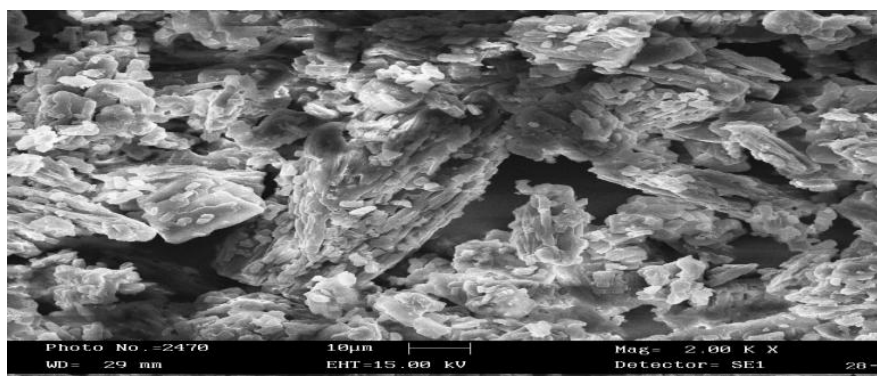

(b) Nicotinic acid (NI)

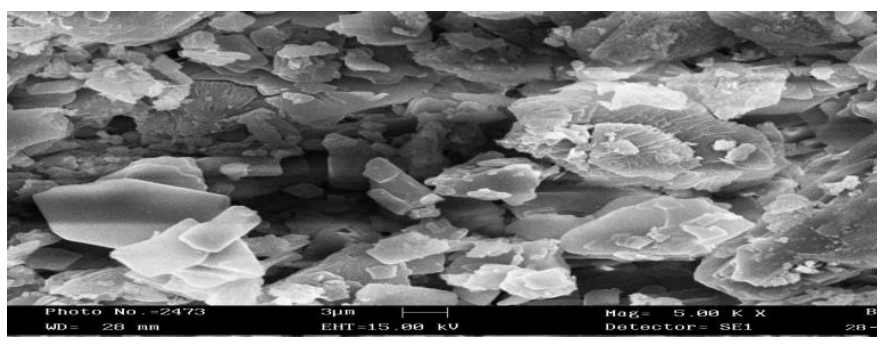

(c) MUSE

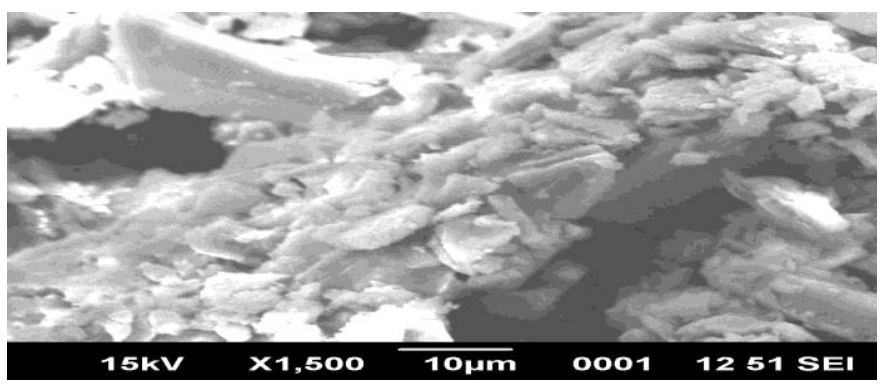

(d) MUSE03

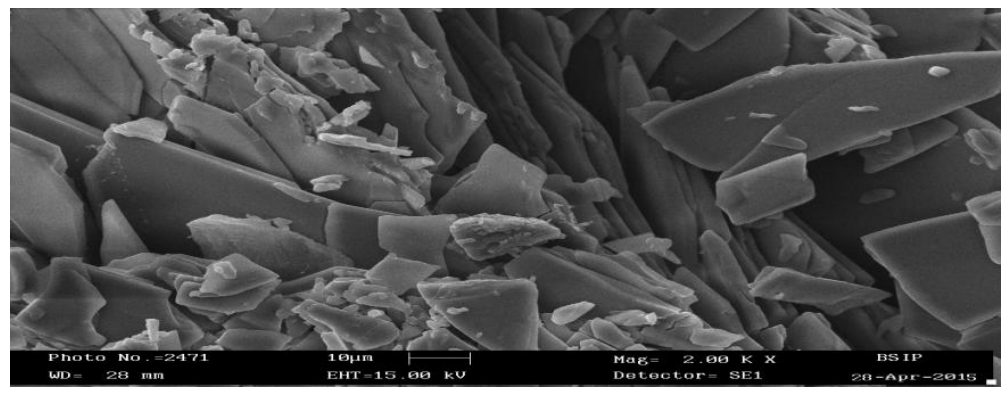

(e) MUSE04

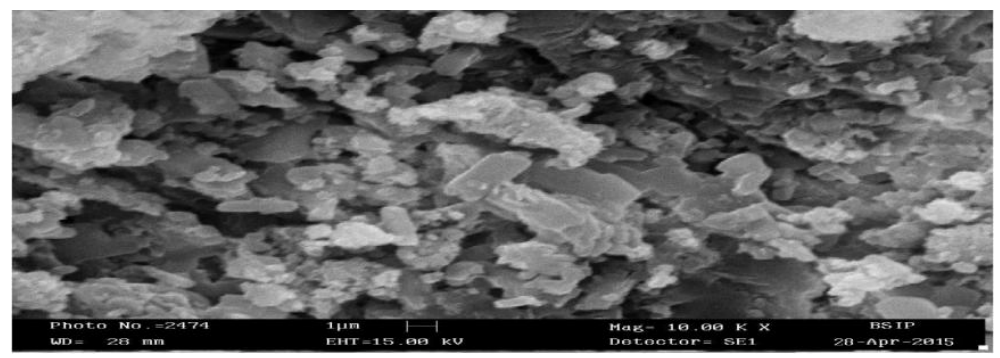

(f) MUNG

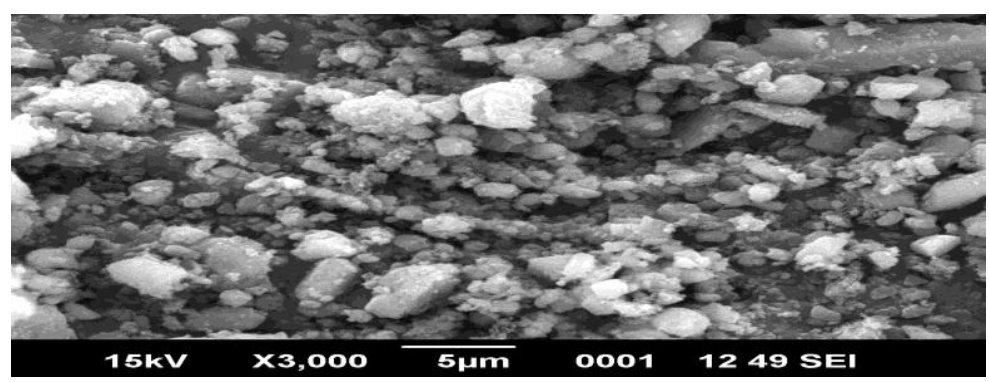

(g) MUNG01

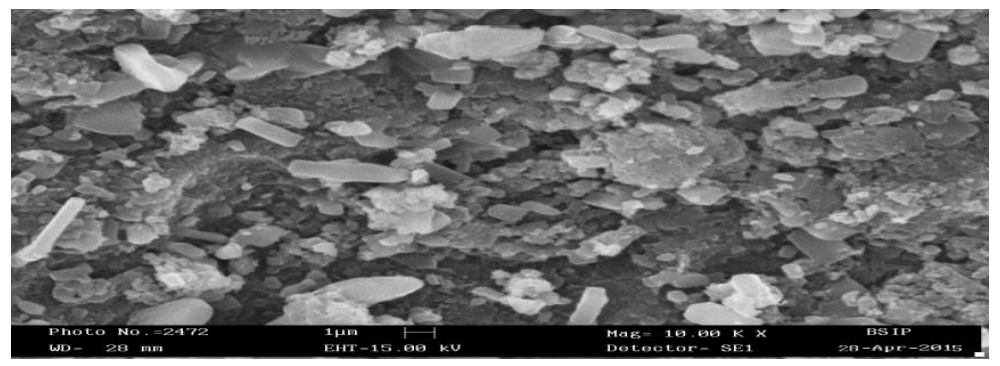

(h) MUNG02

Figure.8. SEM images of (a) Aceclofenac (ACF) (b) Nicotinic acid (NI) (c) MUSE (d) MUSE03 (e) MUSE04 (f) MUNG

(g) MUNG01 (h) MUNG02 
Indo Global Journal of Pharmaceutical Sciences, 2015; 5(3): 154-170

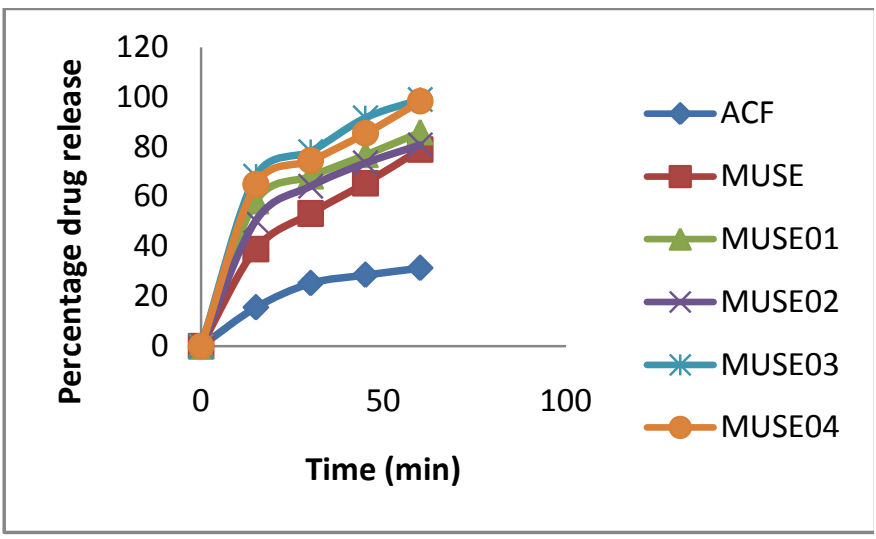

(a)

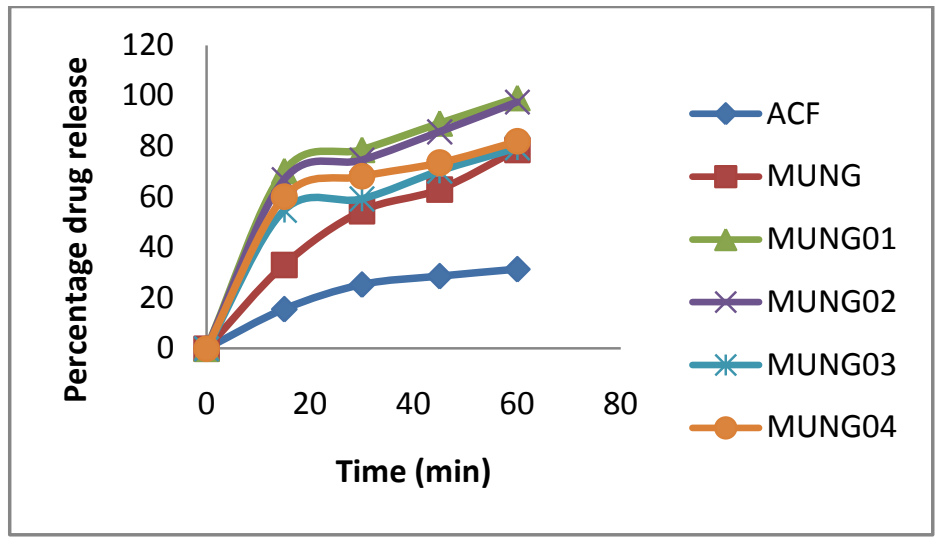

(b)

Figure 9. In vitro dissolution profile of pure drug aceclofenac (ACF) and various aceclofenac cocrystal formulations formed by (a) solvent evaporation method (b) neat grinding method

\section{CONCLUSION}

The aceclofenac-nicotinic acid cocrystal was successfully prepared by using drug aceclofenac (ACF) and cocrystal former nicotinic acid (NI), solvent dimethyl sulfoxide (DMSO) and 3\% water soluble polymers like PVPK-30, HPMCE5, SSG and Na-CMC by both solvent evaporation $\&$ neat grinding method. Pure drug aceclofenac (ACF) showed $31.34 \%$ drug release due to low solubility and dissolution rate of drug aceclofenac. The dissolution rate of drug aceclofenac enhanced by formation of aceclofenac-nicotinic acid cocrystal. (Formulations like MUSE and MUNG showed $78.98 \%$ and $78.51 \%$ drug release respectively). Aceclofenac cocrystal formed by using $3 \%$ water soluble polymers showed maximum dissolution rate enhancement of aceclofenac. (Formulations like MUNG01, MUNG02 MUSE03 and MUSE04 showed drug release 99.1\%, 97.51\%, 99\%, and $98.25 \%$ respectively). This showed that $3 \%$ water soluble polymers like PVPK-30, HPMCE5, SSG and Na-CMC acts as dissolution improving ingredients in aceclofenacnicotinic acid cocrystal. The best formulations are MUSE, MUSE03, MUSE04, MUNG, MUNG01 and MUNG02. The best formulations are further evaluated by FTIR, DSC, PXRD and SEM. The result of analysis of FTIR, DSC, PXRD and SEM confirms the formation of a new solid phase i.e aceclofenac cocrystal.

The aceclofenac cocrystal was successfully prepared and evaluated. The dissolution rate of drug aceclofenac was successfully enhanced by formation of aceclofenacnicotinic acid cocrystal using 3\% water soluble polymers like PVPK-30, HPMCE5, SSG and Na-CMC. The objective of research was successfully achieved hence the study was successful.

\section{ACKNOWLEDGEMENTS}

The authors thank Integrated Biotechnological Research Institute (IBRI), Lucknow, India for providing chemicals and laboratory facility for proposed research work. The authors thank Hygia Institute of Pharmaceutical Education \& Research Lucknow, India for providing chemicals, Instruments and laboratory facility for proposed research work. The authors thank Central Drug Research Institute (CDRI), Lucknow, India for FTIR analysis of sample. The authors thank Sophisticated Test and Instrumentation Centre (STIC), Cochin University of Science and Technology Cochin, India for DSC, PXRD and SEM analysis of sample.

\section{REFERENCES}

1. Blagden, N., de Matas, M., Gavan, P.T., York, P., 2007. Crystal engineering of active pharmaceutical ingredients to improve solubility and dissolution rates. Adv. Drug Deliv. Rev. 59, 617-630.

2. Lu, J., Rohani, S., 2009. Preparation and characterization of theophylline- nicotinamide cocrystal. Org. Process Res. Dev. 13, 1269-1275.

3. Shan, N., Zaworotko, M.J., 2008. The role of cocrystals in pharmaceutical science. Drug Discov. Today 13, 440-446.

4. Miroshnyk, I., Mirza, S., Sandler, N., 2009. Pharmaceutical co-crystals-an opportunity for drug product enhancement. Expert Opin. Drug Deliv. 6, $333-341$. 


\section{Indo Global Journal of Pharmaceutical Sciences, 2015; 5(3): 154-170}

5. Friscic, T., Jones, W., 2010. Benefits of cocrystallisation in pharmaceutical materials science: an update. J. Pharm. Pharmacol. 62, 1547-1559.

6. Shikhar, A., Bommana, M.M, Gupta, S.S, Squillante, E., 2011. Formulation development of Carbamazepine-Nicotinamide co-crystals complexed with $\gamma$ - cyclodextrin using supercritical fluid process. J. of Supercritical Fluids. 55, 1070-1078

7. Qiao, N., Li, M, Schlindwein, W., Malek, N., Davies, A., Trappitt, G., 2011.Pharmaceutical cocrystals: An overview. International Journal of Pharmaceutics. 12057, 1-11

8. Gavhane, Y.N., Yadav, A.V., 2013. Improvement in physicochemical properties of Aceclofenac by using Chitosan and water soluble Chitosan. Int J Pharm Pharm Sci. 5, 414-419.

9. Islam, S.M.A., Islam, S., Shahriar, M., Dewan, I., 2011. Comparative in vitro dissolution study of Aceclofenac Marketed Tablets in Two Different Dissolution Media by Validated Analytical Method. Journal of Applied Pharmaceutical Science. 01 (09), 87-92.

10. Arslan, S.A., Tirnaksiz, F., 2011. A Nonsteroidal Antiinflammatory Drug: Aceclofenac. FABAD J. Pharm. Sci. 35, 05-118.

11. Sarfaraz Md., Arshad Ahmed Khan K., Doddayya H., Reddy S.R., Udupi R.H., 2011. Particle Design of Aceclofenac-Disintegrant Agglomerates for Direct Compression by Crystallo-Co-Agglomeration Technique. Asian J. Pharm. Tech. 1, 40-48.

12. Rajbanshi, K., Bajracharya, R., Shrestha, A., Thapa, P., 2014. Dissolution enhancement of aceclofenac tablet by solid dispersion technique. International Journal of Pharma Sciences and Research. 5, 127-139.

13. Bhide, M.M., Nitave, S.A., 2014. Comparative in vitro evaluation of commercial aceclofenac tablets. World journal of pharmacy and pharmaceutical sciences. 3 , 1678-1687.

14. Retrieved website, September, 28, 2015, pubchem.ncbi.nlm.nih.gov, website pubchem.ncbi.nlm.nih.gov > compound

15. Indian Pharmacopeia, Volume 3, Page Number 825826, Indian Pharmacopeia Commission 2007. ISBN 81-903436-0-3.

16. Retrieved website, October, 1, 2015, wikipedia.org, website https://en.wikipedia.org/wiki/Niacin

17. Retrieved website, October, 6, 2015 wikipedia.org website https://en.wikipedia.org/wiki/Dimethyl sulfoxide

18. Desiraju, G.R., 1989. Crystal engineering: The design of organic solids. Amsterdam: Elsevier.

19. Desiraju, G.R., 1995. Supramolecular synthons in crystal engineering - a new organic synthesis. Angew. Chem. Int. Ed. Engl. 34, 2311-2327.

20. Fukte, S.R., Wagh, M.P., Rawat, S. 2014, Coformer selection: an important tool in cocrystal formation. Int J Pharm Pharm Sci. 6, 9-14.

21. Shah, R., Magdum, C., Patil, S.K., Chougule, D.K., Naikwade, N. 2008. Validated Spectroscopic Method for Estimation of Aceclofenac from Tablet Formulation. Research J. Pharm. and Tech. 1(4), 430432.

Indo Global Journal of Pharmaceutical Sciences( ISSN 22491023 ; CODEN- IGJPAI; NLM ID: 101610675) indexed and abstracted in EMBASE(Elsevier), SCIRUS(Elsevier),CABI, CAB Abstracts, Chemical Abstract Services(CAS), American Chemical Society(ACS), Index Copernicus, EBSCO, DOAJ, Google Scholar and many more. For further details, visit 